\title{
Multimorbidity and quality of life
}

Citation for published version (APA):

Makovski, T. (2022). Multimorbidity and quality of life: epidemiological perspective from the European Region. [Doctoral Thesis, Maastricht University]. ProefschriftMaken.

https://doi.org/10.26481/dis.20220310tm

Document status and date:

Published: 01/01/2022

DOI:

10.26481/dis.20220310tm

Document Version:

Publisher's PDF, also known as Version of record

\section{Please check the document version of this publication:}

- A submitted manuscript is the version of the article upon submission and before peer-review. There can be important differences between the submitted version and the official published version of record.

People interested in the research are advised to contact the author for the final version of the publication, or visit the DOI to the publisher's website.

- The final author version and the galley proof are versions of the publication after peer review.

- The final published version features the final layout of the paper including the volume, issue and page numbers.

Link to publication

\footnotetext{
General rights rights.

- You may freely distribute the URL identifying the publication in the public portal. please follow below link for the End User Agreement:

www.umlib.nl/taverne-license

Take down policy

If you believe that this document breaches copyright please contact us at:

repository@maastrichtuniversity.nl

providing details and we will investigate your claim.
}

Copyright and moral rights for the publications made accessible in the public portal are retained by the authors and/or other copyright owners and it is a condition of accessing publications that users recognise and abide by the legal requirements associated with these

- Users may download and print one copy of any publication from the public portal for the purpose of private study or research.

- You may not further distribute the material or use it for any profit-making activity or commercial gain

If the publication is distributed under the terms of Article $25 \mathrm{fa}$ of the Dutch Copyright Act, indicated by the "Taverne" license above, 
Life expectancy has been increasing for decades due to societal and economic progress and advancements in both clinical medicine and public health. This trend will continue, along with the advantages and challenges it involves. Increased longevity is associated with an accumulation of diseases; hence, the longer one lives the higher the likelihood of living with more than one illness. The current single-disease oriented organisation of health care systems is not optimal for patients with multiple health conditions. And while better care is warranted, more evidence is required to support the most impactful decisions. Patient quality of life (QoL) is an important parameter of quality of care. People with multimorbidity are often considered to be at the highest risk of decreased QoL, which further impedes their health and functioning. Quality of life has therefore emerged as one of the major research goals in the field, thus representing the main focus of this dissertation.

Chapter 1 presents the background, aims and research questions of the thesis. The main aim is to enhance knowledge of multimorbidity, in particular the association between multimorbidity and QoL. Specifically, this thesis focuses on answering the following research questions:

1. What is the operational definition of multimorbidity as compared to comorbidity?

2. What is the strength of the association between disease count and QoL, and what are the relevant elements in the explanation; does the association evolve over time and how does it present across nations?

3. What are the most common disease patterns and how do they relate to QoL?

Chapter 2 highlights a common mistake made in research, the interchangeable use of the terms comorbidity and multimorbidity, and clarifies the difference. Comorbidity is a term which relates to conditions appearing in addition to an index disease, while multimorbidity does not prioritize any of the co-occurring conditions. This distinction is necessary to ensure the clear operationalisation of multimorbidity and its prevalence, as well as for enhancing health care models which may differ for patients with multimorbidity vs. comorbidity. This clarification is also timely considering the ever increasing literature on multiple diseases.

Although several definitions of multimorbidity circulate in the literature, the definition which is consistently used in this thesis is the co-existence of two or more chronic conditions within an individual.

Chapter 3 summarises existing evidence on the association between multimorbidity and QoL with a systematic review, and quantifies for the first time the strength of this association with a meta-analysis. This study explored 25,890 titles on the subject, included 74 studies in the final qualitative synthesis, and subsequently performed 6 case meta-analysis models using 39 studies. The review not only corroborated and reckoned the negative relationship between number of diseases and QoL which progresses with each added condition, but also uncovered additional relevant findings. For example, most of the studies were of a cross-sectional design and disease count was the predominant multimorbidity instrument used to measure the association, assuming a linear trend. However, the review identified a number of other multimorbidity assessment tools. Participant health status was most commonly self-reported, usually from predetermined lists of diseases. The number and types of diseases varied significantly across studies, and researchers applied a broad range of QoL and health related QoL (HRQoL) scales to investigate the association. Therefore, due to clinical and methodological differences, the studies presented high statistical heterogeneity. Meta-analyses demonstrated that the mean reduction in HRQoL for each added disease ranged from $1.6 \%$ to $4.4 \%$, depending on the scale (QoL decline expressed in percentages based on the total scales range of 0-100); the decline was stronger for physical health 
compared to mental health. Stronger negative effect on QoL was also observed among younger populations and women for some, but not all QoL scales. Not accounting for the severity of disease was noted as one of the major shortcomings of using a simple disease count to estimate the association between multimorbidity and QoL. Chapter 4 describes how the systematic review served as a case study for Bayesian hierarchical modelling, a method which is frequently used in cost-utility evaluations. This method combines evidence across different instruments borrowing strengths of each one, while at the same time reducing the uncertainty at the individual instrument level. This is particularly useful for measurements with little evidence which may otherwise be disregarded as insufficiently reliable. Therefore, this method allows expanding information by including all available evidence helpful for decision-making, and in addition increases the precision of the outcome. Healthrelated QoL is a key outcome in cost-utility analysis. In this study, only preference-based HRQoL scales were considered. This study demonstrated the feasibility and usefulness of applying Bayesian hierarchical modelling in synthetizing data on HRQoL; it vastly decreased the level of uncertainty for measurement with the least evidence and provided a more precise estimate of the negative association between number of diseases and HRQoL. The estimate was a 3.8-4.1\% decrease in HRQoL per additional disease, conditional of the instrument. The subsequent chapters present original cross-sectional and longitudinal studies based on the ongoing European survey among community dwelling populations age 50 and older called Survey of Health, Ageing and Retirement in Europe (SHARE). The QoL scale applied in SHARE was the Control, Autonomy, Self-Realization and Pleasure scale (CASP-12v1), rescaled from original values to range from $0-100$, with higher scores indicating higher QoL.

In Chapter 5, thanks to the comprehensiveness of SHARE, the role of various variables in the association between number of diseases and QoL was investigated, in addition to socio-economic circumstances which are most commonly accounted for in similar studies. The sample consisted of 67,179 individuals across 18 countries. Among the tested variables number of symptoms, limitations of activities of daily living (ADL) and instrumental activities of daily living (IADL), perceived social support, and polypharmacy - as an indicator of treatment burden, substantially explained the deterioration in QoL. In fact, these variables reduced the negative association between number of diseases and QoL by $69 \%$, compared to the model adjusted solely for socio-economic characteristics. Number of symptoms contributed the most to this reduction. Initially, QoL decline with each added condition was $2.4 \%$, while the decline was reduced to $0.8 \%$ after the aforementioned relevant factors were added to the model. The effect of number of diseases on QoL was therefore weaker, however still statistically significant. Adjusting for additional factors provided a more precise estimate of the strength of the association, and underlined the relevance of other factors in QoL in the context of multimorbidity. One of the most pertinent contributions of this study was accounting for indicators of treatment burden and signalling the importance it plays in QoL among people with multiple conditions, a matter that has not yet reached sufficient recognition.

The association between disease count and QoL over time was subsequently explored in Chapter 6 . The study observed how the association manifests across European countries and Israel, and investigated the reasons for cross-country differences. In this research, the strength of the negative association remained stable over 10 years for 106,337 participants in 21 countries. The association was however stronger compared to findings from a previously conducted cross-sectional study, resulting in QoL decline of $1.8 \%$ with each new condition. The 
discrepancy most likely originates from methodological differences driven, among others, by fewer adjustment factors and fewer number of diseases in the longitudinal design (16 conditions vs 18 in a cross-sectional design), as only variables present in all study years were considered to ensure consistency. High multimorbidity prevalence was demonstrated by both study designs ( $50 \%$ of the population). Socio-economically deprived population groups displayed lower QoL in this study as in the previous study design, while the stronger negative effect of multimorbidity on QoL for males in the cross-sectional analysis disappeared in this longitudinal observation. A sensitivity analysis which compared models with and without depression in a disease count, revealed in addition a very strong contribution of depression in QoL decline. Countries with higher Gross Domestic Product (GDP) and higher investment in health had a lesser decline in QoL with increasing number of diseases. With regard to regional differences, southern and eastern countries of the European Region displayed a stronger negative effect of increasing disease count.

Exploring the combination of diseases has shown to be very popular and promising in the field of multimorbidity research in recent years in connection to care organisation and prevention planning. In Chapter 7 , the most common disease patterns and their relationship with QoL were explored in 67,179 men and women, using the same dataset as in Chapter 5. Factor analysis generated 3 patterns which were very similar for both sex groups: cardio-metabolic, psycho-geriatric, and mixed. The most prevalent pattern for both men (27.7\%) and women (25.9\%) was cardio-metabolic which combined heart attack, hypertension, high cholesterol, stroke and diabetes. A mixed pattern joined 9 or 10 different pathologies, depending on sex, which was challenging for clinical interpretation. The psycho-geriatric pattern combined Alzheimer's disease and stroke for both sex groups, plus Parkinson's disease and affective disorders for males. The prevalence of the patterns increased with age and patterns overlapped significantly, meaning that an individual could have been counted in more than one pattern. The psycho-geriatric pattern was the least frequent ( $1.4 \%$ of men and $0.3 \%$ of women), but presented the strongest negative association with QoL for women in particular at $5 \%$, vs. $4.5 \%$ for men.

Chapter 8 provides a general discussion of the thesis. This chapter summarises the main findings and deliberates on the methodological strengths and limitations of the research, with specific focus on the applied dataset. Finally, the findings are linked to recommendations for public health policy, clinical practice and research. This thesis confirmed the high prevalence of multimorbidity in the general population on a large sample of middleaged and older adults from across the European Region. It underlined the negative association between multimorbidity and QoL through different study designs and different measurements of multimorbidity, such as disease count and disease patterns. The thesis adds to the growing body of evidence regarding common disease combinations as one of the promising pathways to better care organisation for people with multimorbidity, drawing the attention to the combinations which could be most detrimental to QoL. This study also highlighted the role of additional factors other than burden of disease and socio-economic circumstances that contribute to QoL decline, which could be dealt with better through enhanced care management and public health measures. Further research in this direction will increase awareness of the needs of patients with multiple conditions. This should subsequently guide the design of more optimal, integrated and multidisciplinary patient-centred care, which would translate to improved health outcomes including QoL. 